\title{
A STUDY OF DESIGNING PROCESS FOR TOURISM SUPPORT MOBILE APPLICATION APPLYING PSYCHOLOGICAL EFFECTS
}

\author{
Atsushi Ito ${ }^{1}$, Rina Hayashi ${ }^{2}$, Yuko Hiramatsu ${ }^{3}$, Akira Sasaki ${ }^{4}$ \\ ${ }^{I}$ Professor, Graduate School of Engineering, Information System Science, Utsunomiya University, Tochigi, Japan \\ ${ }^{2}$ Student, Department of Engineering, Information System Science, Utsunomiya University, Tochigi, Japan \\ ${ }^{3}$ Lecturer, Department of Economics, Chuo University, Tokyo, Japan \\ ${ }^{4}$ CEO, GClue Inc., Fukushima, Japan
}

\begin{abstract}
In this paper, we propose a design process of mobile phone application for the sightseeing in Oku-Nikko that is famous for beautiful nature. To make this application useful, we introduced two psychological effects. Firstly, we listed up required elements of sightseeing and categorized into 10 categories. Then we added priority to them based on Maslow's hierarchy of needs. At last, we added priority to functions of a mobile phone application based on the mapping of elements of sightseeing and Maslow's hierarchy of needs. Baes on this analysis, we designed our sightseeing application for Oku-Nikko. For example, all higher priority function (Level 1 and 2 of Maslow's hierarchy) are accessible from home screen and some of them are in the tab bar to be accessible from all screen. We added photo book of seasons on the home screen to use Zeigarnik Effect to encourage visitors to visit Oku-Nikko again in the different seasons. Also, we expect that photo books of nature (mountain, flower, bird) may cause a similar effect.This application will start to use from May 2018, as part of "the Project to Fully Enjoy National Parks" project promoted by The Ministry of the Environment.
\end{abstract}

Keywords: - Tourism support application, BLEBeacon, Psychology of sightseeing, Zeigarnik Effect, Maslow's hierarchy of needs

\section{INTRODUCTION}

All regions face similar challenges in delivering sustainable transport solutions to meet their current and future mobility requirements. Transport authorities are aware of the real needs specific to their region but often find it difficult to identify detailed information on targeted solutions that would deliver direct and tangible positive outcomes.

According to the spread of mobile devices such as a mobile phone, it is expected to use ICT (Information and Communication Technology) for the sightseeing services. In Japan, the Tourism Authority of Japan has started to promote to use a smartphone application to support inbound traveler [35].

Many smartphone applications for sightseeing exist in Japan, through which tourists can obtain information about restaurants, souvenir shops, the weather, and maps. We had 666 applications for local information in 2015. The number of applications did not mean succeed of such contents. It showed us there were no successful contents yet.91\% of them were downloaded less than 10,000 times [10]. The developments are proceeding day by day. However, few users support them.

There are several reasons why users seldom use some local applications for sightseeing. One problem is there are too many applications and usually they are not useful. For example, each application has the original interface and tricky operations. People use navigation applications in their ordinary lives, which show them a map, information of shops and foods etc. They may feel it is enough to have such usual application when they are on the trip, too. In addition, it is important for them to look at landscapes or historic objects when they are on the trip.

The viewpoint of resort side, local government or tourism association assists to create local information application for tourists. Those applications have to publish information about each facility in the same manner. For example, it is difficult to pick up some popular restaurants, since such applications are developed by public money. However, it is not necessarily for tourists to have all information in the area.

We have to consider again that a smartphone is suitable for sightseeing or not. To see the real scenery and enjoy activities are the main purpose of sightseeing. Also, we usually take photos and post them to SNS such as Facebook and Instagram, so that a smartphone has an important role for the sightseeing. In addition, visitors would like to know information about their interest or some popular sightseeing points of their destination by using a smartphone. 
Such applications provide much information relating to sightseeing, however, why the information was selected and how the application was designed are not clear.

In this paper, we would like to propose a design process for sightseeing application based on psychological effects. Oku-Nikko is used as an example to explain our design process.

There are studies to analyze motivation, decision process to select a destination using psychology [17], however, there is no research to analyze priority of information during a travel based on psychological effects. So that, we would like to propose design method to categorize information for sightseeing and to decide the priority of them. Using the method, we think it is possible to design useful smartphone application to support sightseeing.

The followingis our approach to design an application for sightseeing. We would like to explain details of each step in this paper.

List up elements of sightseeing

Add priority to these elements

List up functions for an application for sightseeing

Design UI of application

In section 2, we explain our previous work and related works are explained in section 3. In section 4, we firstly categorize elements of travel. Then we explain two psychological effects, Zeigarnik Effect and Maslow's hierarchy of needs, and how to use them for sightseeing application in section 5. In section 6, we explain the mapping among elements of travel, Maslow's hierarchy of needs and required function of sightseeing application. Then we define the priority to the required function. In section 7 , we mention how our application is designed by using priority of functions. Finally, we conclude this paper in section 8 .

\section{OUR PREVOUS WORK}

From 2014 to 2016, Utsunomiya University and Chuo University have studied on developing sightseeing support system using BLE (Bluetooth Low Energy [1,2]) beacon in Nikko, one of the world cultural heritage in Japan $[3,4,5]$. Development of this system was performed as a project of SCOPE (Strategic Information and Communications R\&D Promotion Programme) [6] funded by Ministry of Internal Affairs and Communications in Japan [7]. The title of this research was "A Study on Information Delivery System to Increase Satisfaction of Tourist". The aim of the research was how to increase the satisfaction of tourists and increase the number of repeaters by using ICT. The SCOPE project finished in 2016, and now we are continuing this research as one of the projects of JSPS KAKENHI Grant [8] as "Touristic Resource Development through ICT - how to increase expectation using psychological effects -".

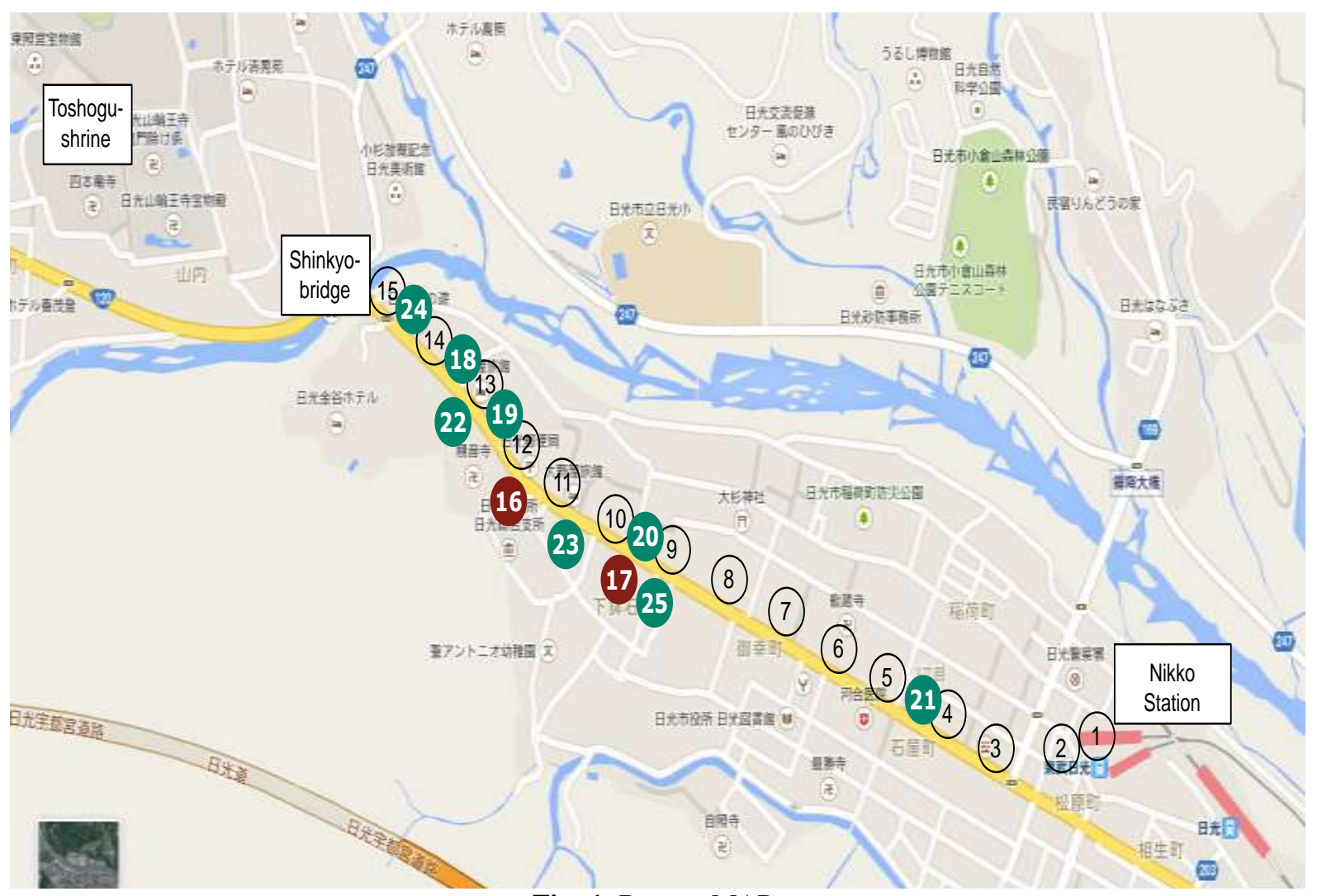

Fig -1: Beacon MAP 


\subsection{Nikko}

Nikko [18] was registered as one of the world cultural heritage on December $2^{\text {nd }}, 1999$. It is, however, that the number of visitors is not increasing so much after the registration as world cultural heritage. Especially, the number of visitors who stay Nikko is decreasing. For example, the number of visitors who stay Nikko in 2002 decreased 7\% compared to that of in 1998 [9]. There are several reasons why Nikko did not become more popular after registered as world cultural heritage. We think that one of the biggest problems is that Nikko is already too famous to attract additional tourists. In another word, there is not so much "novelty" in Nikko as a resource for sightseeing. Many Japanese who grow up near Tokyo have the experience to visit Nikko as a school trip. However, they did not have good image and impression in Nikko since history and culture in Nikko is not so much attractive for children.

Traditionally, traveling is getting away from daily life. Visiting unknown places is one of the great pleasures. We can discover many things such as a hidden history of a village, original culture, and wild nature. "Discover" means "dis"="unveil" "cover", so a travel gives us new information. The dream to discover unknown parts of the world brings us to unknown places. The satisfaction is not proportional to the amount of information.

We started a study to investigate what is the most attractive aspect of travel and how to increase expectation and satisfaction of travel in Nikko [18]. Nikko is one of the world heritages in Japan. There is the Toshogu-shrine [19] that is a gorgeous grave of Ieyasu Tokugawa who is the first Shogun of Tokugawa Era. However, now, Nikko is not so famous for foreigners. A research by travel agency displayed that Nikko is not listed in top 30 locations where foreigners would like to visit [20].

\subsection{Nikko KamenNavi}

In our system, 21 BLE beacons were installed on the road from Tobu and JR Nikko Station to the entrance of Toshogu-shrine through Shinkyo-bridge as described in Fig1. White and red circle are the beacons that were installed in outdoors (Fig-2). Beacons in shops are 15.
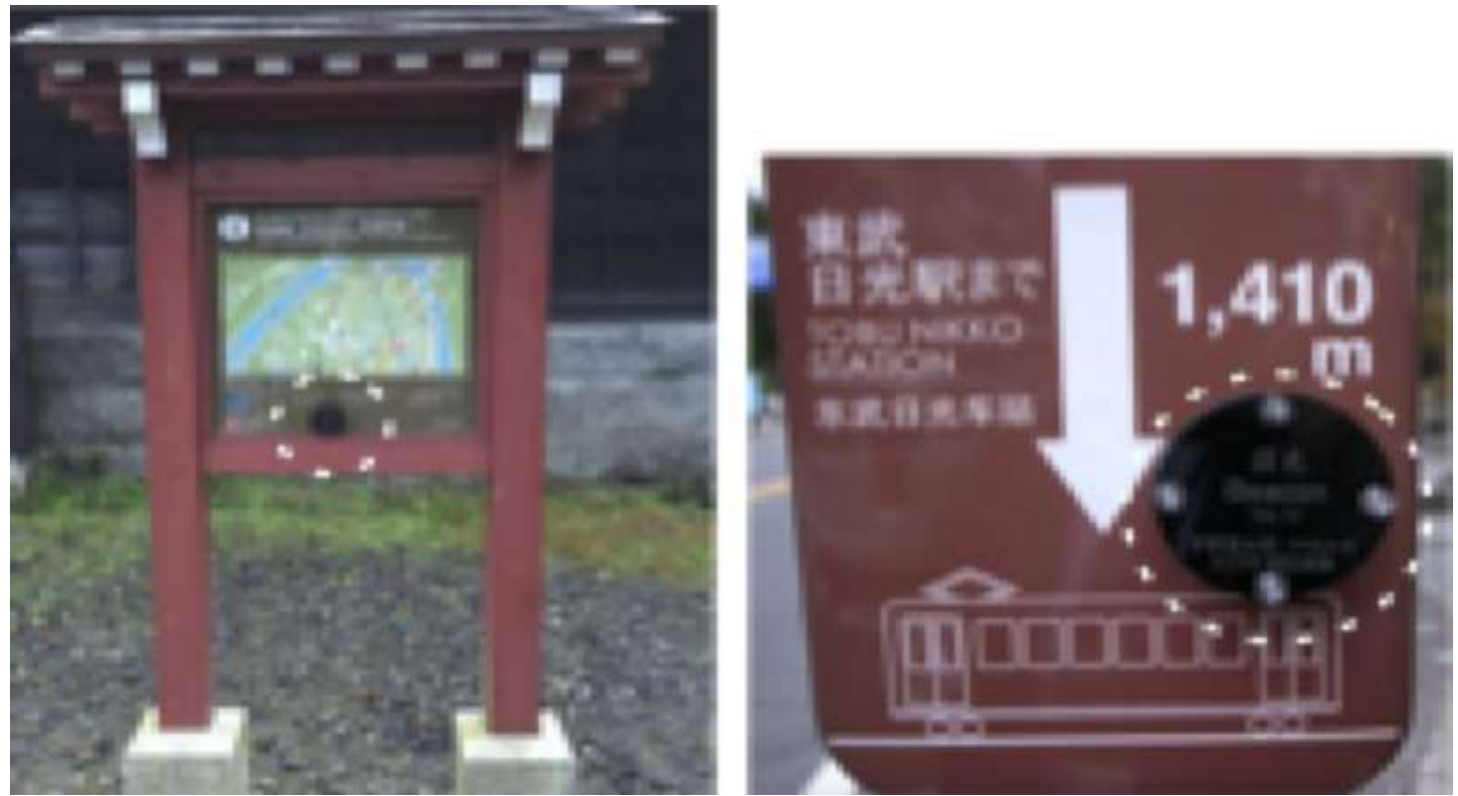

Fig -2: BLE Beacon on the road (in dotted circle)

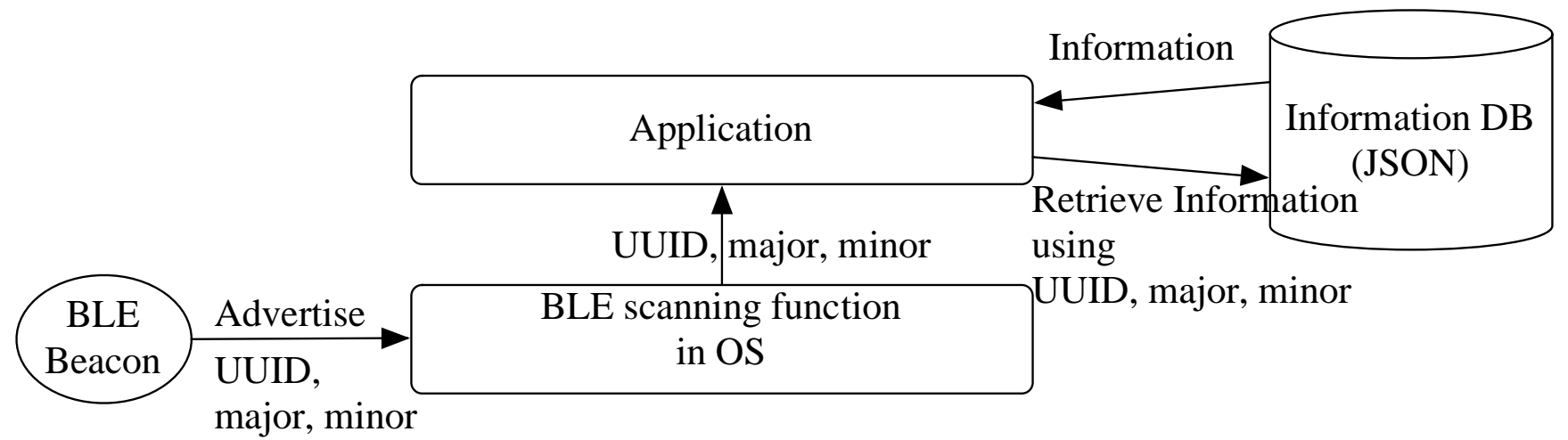

Fig -3: Relationship between a beacon and mobile phone 
Each beacon contains an index of information related to its location. For example, when the application receives a signal from beacon \#13, the application displays "On the left, there is a slope. At the end of the slope, there is an old temple, named Kannonji, $180 \mathrm{~m}$ to Shinkyo Bridge and $1,250 \mathrm{~m}$ to Nikko train station." A visitor can use this message and will find a small, historic temple where they cannot find if they are walking the road straight. Fig-3 shows the relationship between a beacon and mobile phone. In the operating system (OS), BLE access function always scans advertising message. If the OS catches it, the information of the advertising message is forwarded to the application. For example, Core Location framework of iOS (7 or later) provides three properties such as UUID, major and minor. Android 5.0 or later also has the similar function. If the information such as UUID, major and minor is received from a beacon, the application retrieves information that matches triples (UUID, major and minor).

The name of our application is called "Nikko Kame Navi" and provided on the iTunes Store and Google Play. Fig-4 shows some screenshots of "Nikko Kame Navi". This application supports four languages, Japanese, English, Chinese (traditional Chinese character) and Thai.
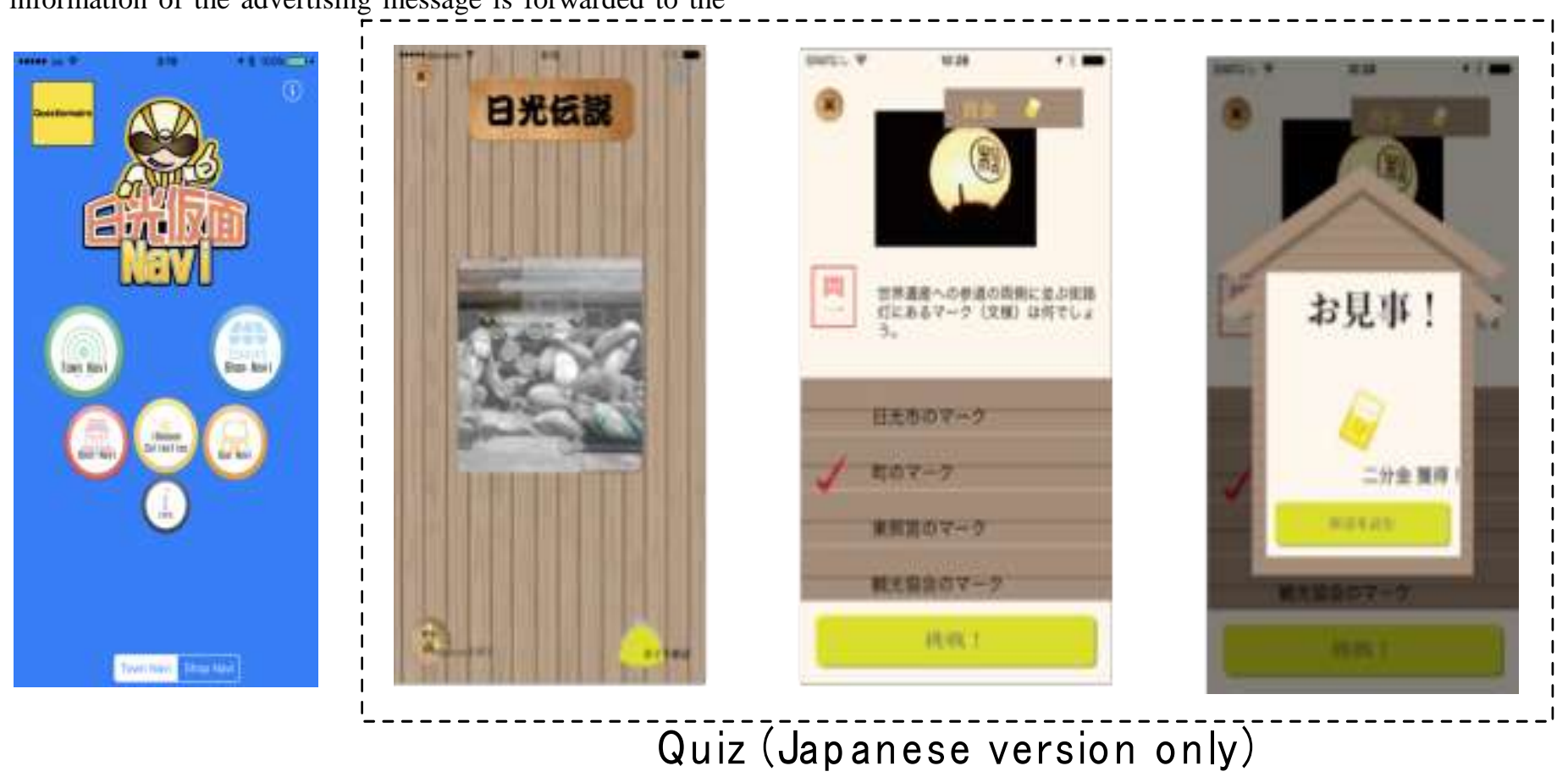

Fig -4: Screen shots of "NikkoKamenNavi"

\subsection{Our Cognitive Model of Sightseeing}

In our system, 2 How to provide information to feel and understand culture and history of Nikko area? And how to increase visitors and repeaters?

We focused on "Zeigarnik Effect [12]" for that purpose. Zeigarnik effect carries the name of BlumaZeigarnik, a Lithuanian-born psychologist. This effect explains that completed tasks are less recalled than uncompleted tasks. For the Zeigarnik effect, a study made by Greist-Bousquet and Schiffman in 1992 [13] provided evidence. Zeigarnik Effect explains that a desire or stress to complete uncompleted part can keep memory longer. In another word, Zeigarnik tasks that have been completed are recalled less well than tasks that have not been completed. Nowadays all the applications provide detailed navigation functions for trips, however, we would like to create the incomplete experience based on the Zeigarnik effect.

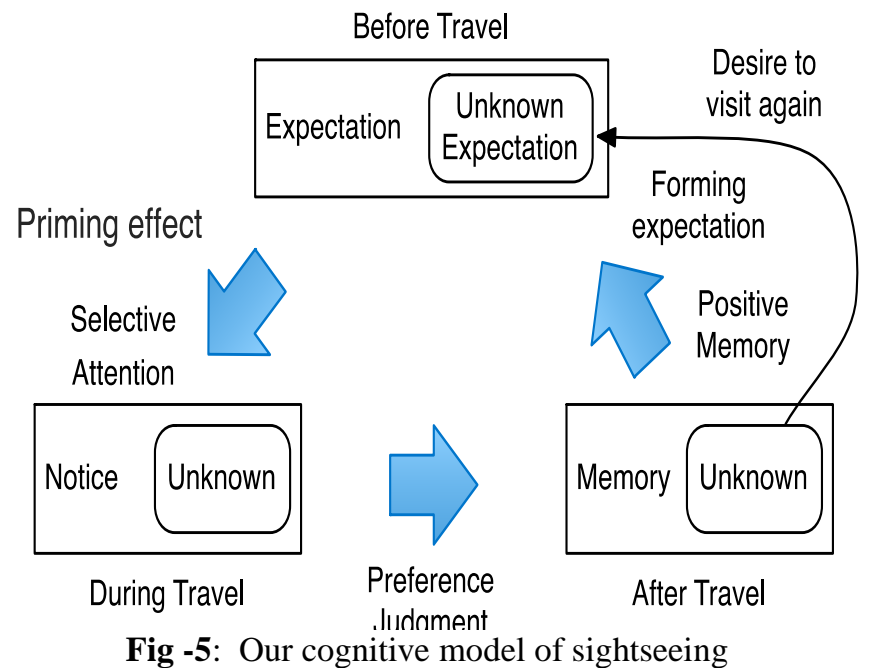

Fig-5 explains our cognitive model for sightseeing. We developed this model based on the Zeigarnik effect and our research on modeling of expectation $[21,22]$. In the ordinary 
cognitive model of sightseeing, simple loop of three stages, Expectation (before travel) $\Rightarrow$ Notice (during travel) $\Rightarrow$ Memory (after travel), is used (Fig-6).

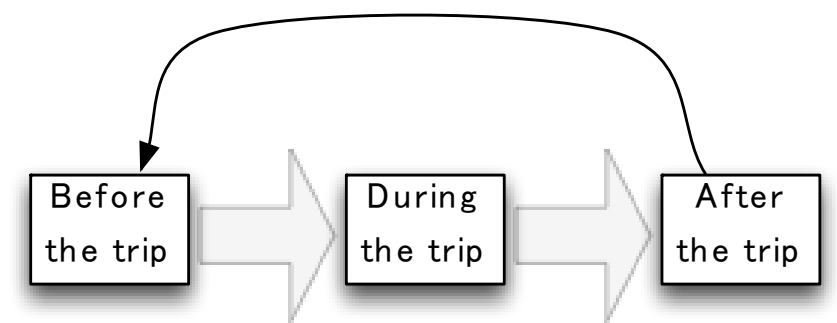

Fig -6: Three stages of sightseeing.

In our model of sightseeing (Fig-5), if a visitor finds unknown part of the visited area, Zeigarnik effect causes strong memory that remains after the travel. Then the memory extended and emphasized by unknown part causes unknown expectation and generate a desire to visit there again. We evaluated and proved the effect of quizzes to make an unknown part [3,4,5]. For example, if I do not know the answer to the question about Toshogu-shrine, such as "The roof of Hall of worship of Toshogu-shrine has 100 pictures of dragons. How many fingers do they have?". This is not an easy question. It is difficult to answer it at the first time so that the image of "picture of dragons" may be kept in my memory and I would like to see the picture or would like to see it again.

Table -1: Result of cluster analysis

\begin{tabular}{|c|c|c|c|}
\hline Evaluation point & Cluster1 & Cluster2 & Cluster3 \\
\hline Impression & 3.29 & 4.57 & 3.25 \\
\hline Interface & 4.00 & 4.14 & 3.25 \\
\hline Usability & 3.00 & 3.71 & 3.25 \\
\hline Character size & 4.14 & 4.00 & 4.00 \\
\hline Sound & 4.43 & 3.29 & 3.25 \\
\hline Color & 4.57 & 4.29 & 3.25 \\
\hline Expression & 4.29 & 3.86 & 3.25 \\
\hline Contents(Quiz) & 3.14 & 4.14 & 4.25 \\
\hline Visibility of the map & 3.43 & 3.29 & 5.00 \\
\hline
\end{tabular}

Table -2: Comparison of the results between two months

\begin{tabular}{|c|c|c|c|c|c|c|c|}
\hline \multicolumn{4}{|c|}{ Just after visit } & \multicolumn{4}{|c|}{2 months after } \\
\hline questions & Cluster1 & Cluster2 & Cluster3 & questions & Cluster1 & Cluster2 & Cluster3 \\
\hline Nature & 4.57 & 4.86 & 4.00 & Nature & 4.43 & 4.83 & 4.50 \\
\hline History/Culture & 4.29 & 5.00 & 3.50 & History/Culture & 4.43 & 4.80 & 4.75 \\
\hline City Scape & 4.14 & 3.86 & 4.00 & City Scape & 4.00 & 3.83 & 4.00 \\
\hline Hot Spring & 4.00 & 3.71 & 3.50 & Hot Spring & 3.57 & 3.50 & 3.25 \\
\hline $\begin{array}{l}\text { Traditional } \\
\text { culture }\end{array}$ & 3.43 & 3.86 & 3.00 & $\begin{array}{c}\text { Traditional } \\
\text { culture }\end{array}$ & 3.71 & 3.83 & 4.00 \\
\hline Foods & 3.86 & 4.00 & 3.50 & Foods & 3.71 & 3.83 & 4.75 \\
\hline Activity & 3.00 & 3.43 & 2.25 & Activity & 3.00 & 2.83 & 3.75 \\
\hline Shopping & 3.00 & 3.29 & 2.75 & Shopping & 3.00 & 3.17 & 3.75 \\
\hline Night Spots & 2.86 & 2.71 & 3.50 & Night Spots & 3.00 & 2.67 & 3.00 \\
\hline $\begin{array}{l}\text { Interaction with } \\
\text { local people }\end{array}$ & 3.00 & 3.43 & 2.25 & $\begin{array}{l}\text { Interaction with } \\
\text { local people }\end{array}$ & 3.71 & 3.33 & 3.00 \\
\hline $\begin{array}{l}\text { Reservation of } \\
\text { Accommodation }\end{array}$ & 3.14 & 3.29 & 3.50 & $\begin{array}{l}\text { Reservation of } \\
\text { Accommodation }\end{array}$ & 3.00 & 3.17 & 3.00 \\
\hline $\begin{array}{l}\text { Price/quality of } \\
\text { Accommodation }\end{array}$ & 3.43 & 3.71 & 3.25 & $\begin{array}{l}\text { Price/quality of } \\
\text { Accommodation }\end{array}$ & 3.00 & 3.17 & 3.50 \\
\hline $\begin{array}{l}\text { Convenience of } \\
\text { Access }\end{array}$ & 3.86 & 4.43 & 2.75 & $\begin{array}{c}\text { Convenience of } \\
\text { Access }\end{array}$ & 3.29 & 3.50 & 1.75 \\
\hline Price & 3.14 & 3.43 & 2.25 & Price & 3.00 & 3.83 & 3.25 \\
\hline
\end{tabular}

In 2016, we tried to evaluate the effectiveness of our cognitive model from a different viewpoint, in another word, how this model increase impression of Nikko. For that purpose, we performed these trials from Spe. 2016 to Dec. 2016. 18 students cooperated this trial. Students visited Nikko when they could find the time. When they arrived at Nikko station, they started to walk to visit Toshogu-shrine following navigation of the application and answering quizzes. Just after they finish sightseeing, we asked them to answer two questionnaires, one questions on impression about the application (5 levels Liker scale) and another question on impression of Nikko (5 levels Liker scale). Then two months after, we asked them to answer the same questions on impression of Nikko to check the effect of using application, especially trying quizzes, to remain and emphasize the memory of Nikko. Outline of this trials is described in Fig-7. After we received answers from students, we analyzed them to classify the impression of "Nikko KamenNavi" by using principal component analysis and cluster analysis (Ward's method) in SPSS v23. We got 3 clusters. Cluster $1(n=7)$ were persons who appreciated sound, color, and expression. Cluster $2(n=7)$ appreciated overall impression and UX. Cluster $3(n=4)$ appreciated quiz contents and visibility of the map. Table-1 shows the average of the score as the result of this step. Two months after, we compared answers of the impression of Nikko, one is the answer of just after trial and another is that of two months after. Table- 2 shows the comparison of 2 results. Each cell shows the average of the score in each cluster. A cell with color is the question that scores increased. In 
Cluster 1, the score of two questions increased and in Cluster 2, the score of only one question increased. On the other hand, in Cluster 3, the score of nine questions increased. In Table-2, there are two colors in the cells, one is light and another is dark. The dark color means that the difference of score is +1 or larger. The light color means the difference is less than +1 . Cluster 1 and 2 do not have a dark colored cell and only Cluster 3 has such cells. This result means that Cluster 3 has a better impression in Nikko than other two clusters. This result means that who appreciated contents had the strong memory of Nikko, especially culture and history. We can conclude that this is one of the evidence to prove the effectiveness of our cognitive model for sightseeing. If it is possible to generate satisfaction and expectation by quizzes, it may also be possible to increase a positive impression of Nikko.

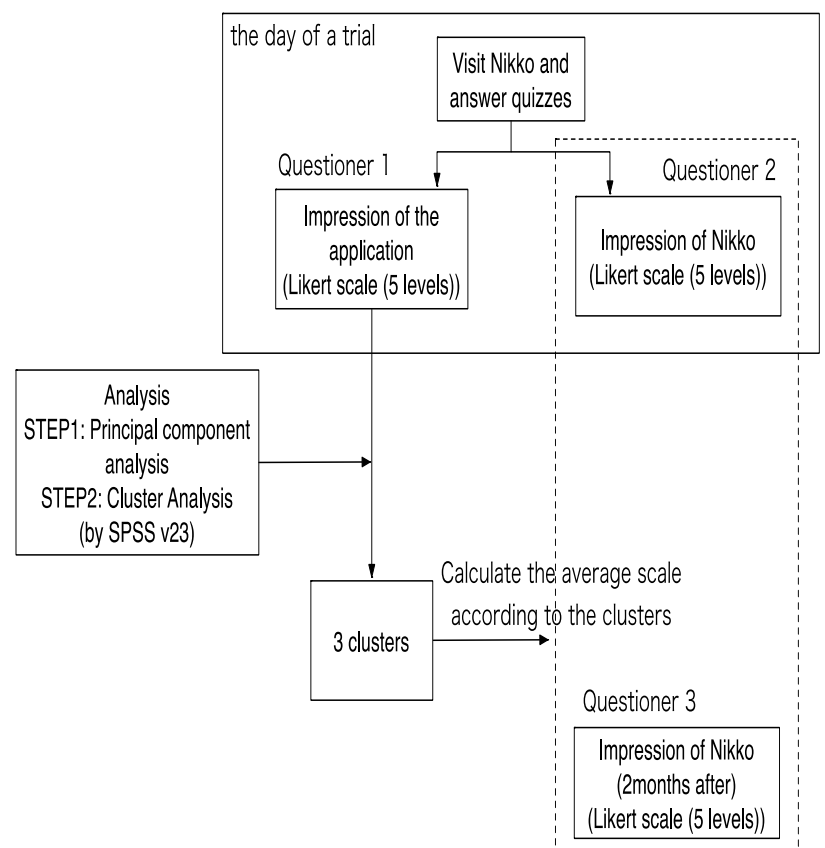

Fig -7: Outline of the trial and Analysis

Our previous research focused on the sightseeing of the cultural heritage in Nikko. The assets of the sightseeing in Nikko are history and culture, however, there are different assets of sightseeing in Oku-Nikko such as beautiful nature. In this research, we explain how we analyzed the features in Oku-Nikko and designed our application for sightseeing in Oku-Nikko from section 4.

\section{INTRODUCTION}

\subsection{Sightseeing Support Application}

In the EU, The TAG CLOUD (Technologies lead to Adaptability \& lifelong enGagement with culture throughout the CLOUD) project is a remarkable system using smartphone technology to provide information about traditional cultural sites [11]. This project by the Community Research and Development Information Service was launched to investigate ways of enabling cultural engagement using cloud-based technologies to show cultural heritage contents to tourists using RFID tags. Also, the TAG CLOUD is a cloud service. It means that tourists have to contact the Internet. On the other hand, our application is designed to work without the cloud. Because the Internet access for tourists is sometimes limited in rural areas.

Also, there are many studies on sightseeing application. [27] explains the application to provide personalized sightseeing information. [28] is an application for cultural heritage recommendation. [29] also discusses on a platform of sightseeing application for cultural heritage, and [30] discusses on ubiquitous indoor navigation without a smartphone.

However, a sightseeing application using BLE beacon in a town is rare and also designed based on the psychological model is also rare.

\subsection{Psychology for Tourism}

There are several works about Environmental psychology and tourism. Pearce \& Stringer [14] studied from the viewpoint of physiology, cognition and individual variation etc. Fridgen [15], van Raaij [16], T.Sasaki also studied this field. Especially, T.Sasaki mentioned that we can part a trip into 3 scenes: before the trip, during the trip, and after the trip [17] (See Fig-6). It means that a trip is not only enjoying the trip but also planning to increase expectation before the trip and remember the memory of the trip after returning home.

\section{CATEGORIES OF ELEMENTS OF A TRAVEL}

Traditionally, the psychology of sightseeing separates a travel in three stages, such as before a travel, during the travel and after the travel, as described in Fig-5 and Fig-6. According to [17], the trigger of travel is a desire for novelty. However, these studies do not contain the analysis of required information during a sightseeing.

Our research is focusing on this part and propose a design method for an application for sightseeing based on psychology.

We firstly classified the information required for a sightseeing into 10 categories as described in Fig-8.

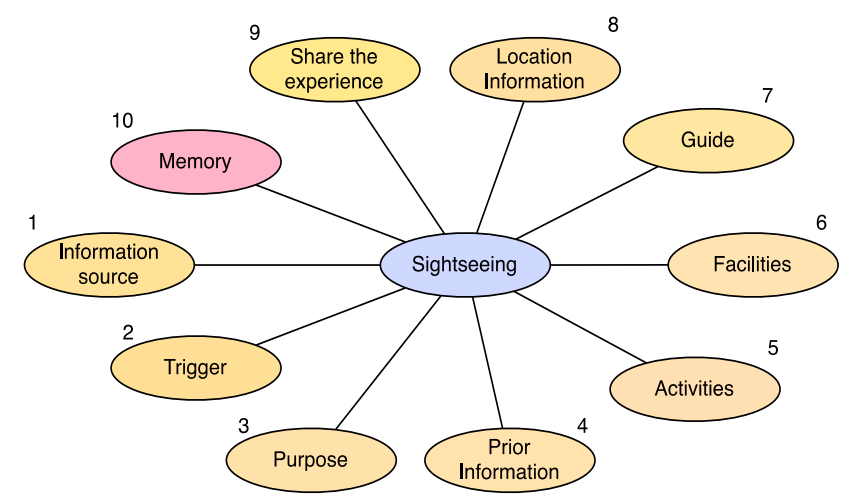

Fig -8: Categories of information required for a sightseeing 
From 1 to 4 in Fig- 8 are relating to motivation to go sightseeing.

1. Information source: Tools used to find information relating to the destination before and during a sightseeing. (Home Page, book, magazine, travel agency, information from friends, SNS, Direct Mail (DM) etc.)

2. Purpose: The purpose of a sightseeing. (Hot spring, Gourmet, Nature, Scenery, Shopping, Festival, Event, Attraction, Theme park etc.)

3. Trigger: Cue to go to a sightseeing. (1. Information source, 2. Purpose)

4. Memory: Positive memory to be a repeater based on the previous trip

From 5 to 7 are relating to logistics to go to sightseeing.

5. Prior information: Information relating to the destination area. (Transportation, access, accommodation, WiFi, model course, weather, price, regional products, activity etc.)
6. Activities: Something to see or to do at the destination area. (Gourmet, event, attraction, high light, model course, facilities etc.)

7. Facilities: Information of facilities in the destination such as museums, parking lot, restroom (fee, opening hour, reservation, congestion etc.)

From 8 to 10 are relating to information required during sightseeing.

8. Guide: Information to look around the destination. (Guidance of the area, model route, history, information of origin, effect of hot spring etc.)

9. Location information: Map and navigation.

10. Share the experience: Activity to share the impression of the destination. (SNS, Blog, Write comments on HP, postcard, letter, email etc.)

Fig-9 is the big picture of information relating to sightseeing.

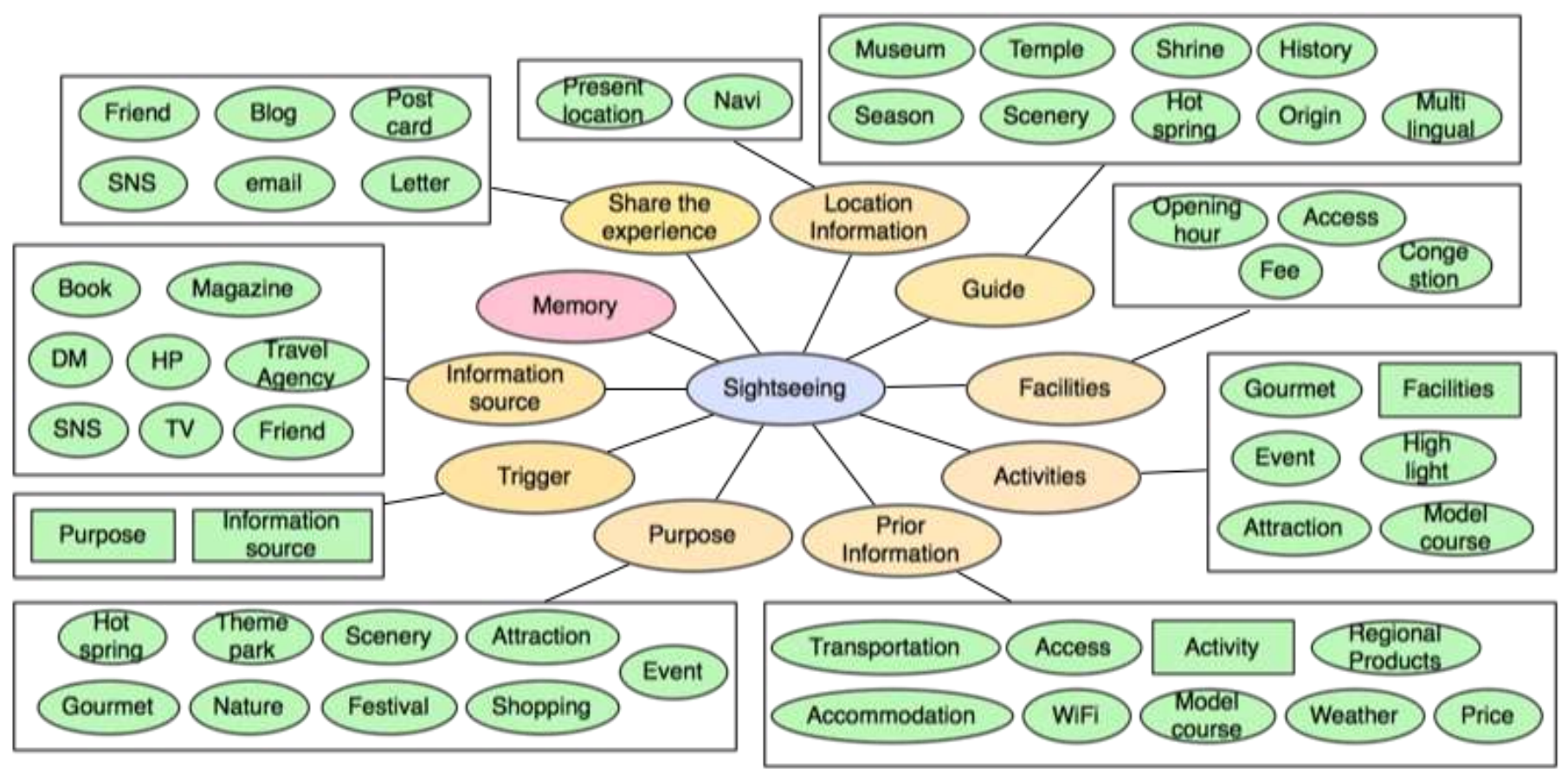

Fig -9: Elements of information for sightseeing

\section{PSYCHOLOGICAL EFFECTS USED IN OUR} SIGHTSEEING APPLICATION FOR OKU-

\section{NIKKO}

We used two psychological effects in our sightseeing application for Oku-Nikko. One is Zeigarnik Effect and another is Maslow's hierarchy of needs. In this section, we would like to explain how to use these psychological effects to design sightseeing application.

\subsection{Zeigarnik Effect}

As explained in section 2.3, Zeigarnik Effect explains that a desire or stress to complete uncompleted part can keep memory longer. In another word, Zeigarnik tasks that have been completed are recalled less well than tasks that have not been completed.

In the case of a sightseeing trip, if there is something uncompleted, the memory of the trip may remain longer and be a trigger to visit there again. As explained in section 2.3, the effectiveness of Zeigarnik Effect for sightseeing application was proved. 
For the application for Oku-Nikko, we would like to use Zeigarnik Effect as follows. If someone visits Oku-Nikko in autumn, the application displays photos of scenery filled by cherry blossoms in spring or that covered by white snow with a footprint of fox in winter. The visitor may be attracted by those photos and it is expected that the memory of Oku-Nikko becomes stronger and the visitor becomes a repeater.

\subsection{Maslow's Hierarchy of Needs}

Maslow stated that people are motivated to achieve certain needs and that some needs take precedence over others [31, 32]. Our most basic need is for physical survival, and this will be the first thing that motivates our behavior. Once that level is fulfilled the next level up is what motivates us, and so on. The lower need is more important and has higher priority. He developed different types of the hierarchy of need such as 5 layers model and 8 layers model. In our research, we used 7 layers model (Fig-10) since this model meets classification of information required for sightseeing.

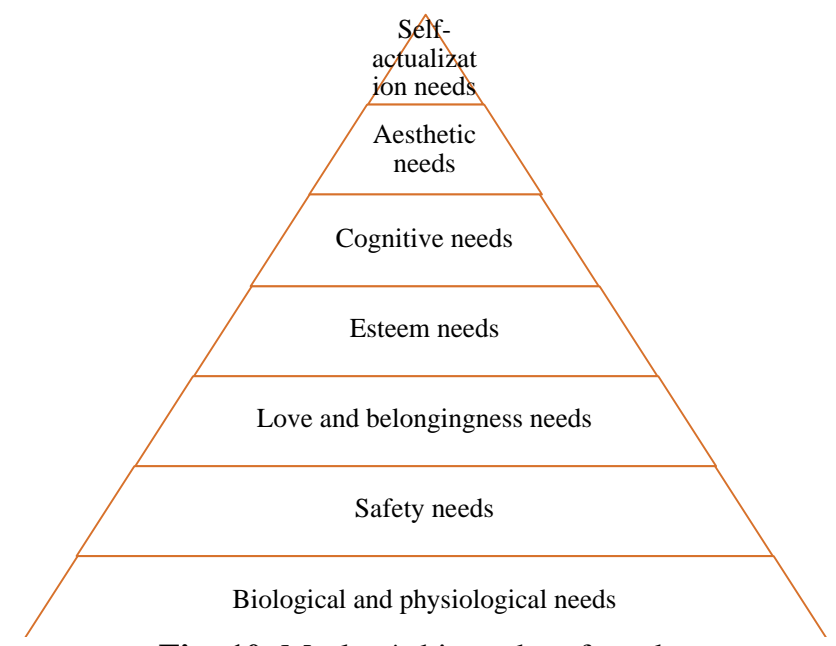

Fig -10: Maslow's hierarchy of needs

Level 1. Biological and physiological needs - air, food, drink, shelter, warmth, sex, sleep, etc.

Level 2. Safety needs - protection from elements, security, order, law, stability, etc.

Level 3. Love and belongingness needs - friendship, intimacy, trust, and acceptance, receiving and giving affection and love. Affiliating, being part of a group (family, friends, work).

Level 4. Esteem needs - (i) esteem for oneself (dignity, achievement, mastery, independence) and (ii) the desire for reputation or respect from others (e.g., status, prestige).

Level 5. Cognitive needs - knowledge and understanding, curiosity, exploration, need for meaning and predictability. Level 6. Aesthetic needs - appreciation and search for beauty, balance, form, etc.

Level 7. Self-actualization needs - realizing personal potential, self-fulfillment, seeking personal growth and peak experiences.
We applied this idea to design our application for sightseeing in Oku-Nikko.

\subsection{Mapping between Maslow's Hierarchy of Needs and Elements of Sightseeing}

Table-3 shows the mapping between Maslow's hierarchy of needs and elements of sightseeing that is described in section 4.

Table -3: Mapping between Maslow's hierarchy of needs and elements of sightseeing

\begin{tabular}{|l|l|}
\hline \multicolumn{1}{|c|}{ Hierarchy of needs } & \multicolumn{1}{c|}{ Elements of sightseeing } \\
\hline $\begin{array}{l}\text { Level } 1 \text { Biological and physiological } \\
\text { needs }\end{array}$ & Food (stores)[ Restroom \\
\hline $\begin{array}{l}\text { Level } 2 \text { protection from elements, } \\
\text { security etc. }\end{array}$ & $\begin{array}{l}\text { Transportation, Access, Accommodation, WiFi, Price, } \\
\text { Weather, Congestion, Disaster relief, Alert of risk, } \\
\text { Map, Multi lingual assist }\end{array}$ \\
\hline Level 3 Love and belongingness needs & SNS, Blog, email, Letter, Post card \\
\hline Level 4 Esteem needs & "like", Reaction for the articles, Reply for mail \\
\hline Level 5 Cognitive needs & Guidance, Model course, Event, High light \\
\hline Level 6 Aesthetic needs & $\begin{array}{l}\text { History, Origin, Hidden knowledge } \\
\text { Photo and explanation of scenery, animals and flowers }\end{array}$ \\
\hline Level 7 Self-actualization needs & $\begin{array}{l}\text { Coincidence of expectation and experience } \\
\text { Achievement of purpose }\end{array}$ \\
\hline
\end{tabular}

\section{ANALYS OF ELEMENTS OF SIGHTSEEING} AND PRIORITY OF THEM

\subsection{Information Required for Sightseeing in Oku-}

\section{Nikko}

Oku-Nikko is west part of Nikko. This area is famous for a great nature such as forest, lake, mountain, river, waterfall and large marshland called "Senjyo-gahara". We can see a different kind of flowers, birds, and animals in Oku-Nikko and we can enjoy hiking, mountain climbing, fishing, bird watching etc. in this area so that many people visit this area in all season from many countries.

Many tourists visit Nikko, over 10 million people per year, to see Toshogu-shrine, however, almost all of them do not visit Oku-Nikko. One of the reasons is the access to OkuNikko is difficult to understand.

We performed an interview with visitors in Nikko area and Oku-Nikko area on September 2,3, 2017 to investigate images and impression on Oku-Nikko. We performed the interview at Nikko station (Tobu and JR), Nikko Natural Science Museum [34], Visitor center in Yumoto and Akanuma, and rest area in Senjyo-gahara. The target was both Japanese (125) and foreigners (24). Typical answers were as follows. 
Have image of Oku-Nikko: 70 persons $(56 \%) \Leftrightarrow$ No idea: 14 persons $(11.2 \%)$

If they answered to have an image of Oku-Nikko, their images were "nature", "beautiful" and "quiet".

From the result of the interview, we thought that many visitors in Nikko may have an unclear image of Oku-Nikko, however, they may have no idea of famous sightseeing spots and access to Oku-Nikko.

We also asked them what kind of information is required if they use an application to guide Oku-Nikko. The answers were as follows.

- Restroom

- Water place

- Name and photo of birds

- Seasonal information

- Information of bus route and timetable

- Opinion and recommendation from specialists

- Guide of Senjyo-gahara to walk safely

\subsection{Priority of Information for Sightseeing in Oku-}

\section{Nikko}

Based on the elements of sightseeing (Table-3), we listed up the following functions that should be implemented in an application of Oku-Nikko.

- Weather

- Information

- Bus time table

- Map (present location, visitor center, restroom, rest house)

- Information (information of nature, information on the sign board, shops)

- Photos in different seasons (Spring, Summer, Autumn,Winter)

- Picture book (birds, flowers and mountains)

- Stamp rally

- Pop up information according to location of a beacon

- $\quad$ SNS

- $\quad$ Setting

Table-4 shows mapping among elements of information, Maslow's hierarchy of needs and functions of the application. In the next section, we would like to explain how we designed based on the analysis described in this section.

Table -4: Mapping among elements of information, Maslow's hierarchy of needs and functions of application

\begin{tabular}{|c|c|c|c|c|c|}
\hline \multirow{2}{*}{ Elements of sightseeing (Oku-Nikko) } & \multicolumn{4}{|c|}{ Levels of needs } & \multirow[t]{2}{*}{ Function of App } \\
\hline & $1 \quad 2$ & 3 & $4 \quad 5$ & $\begin{array}{ll}5 & 6 \\
\end{array}$ & \\
\hline Weather & 0 & & & & Weather \\
\hline New Information (Weather, Disaster, Bear, Event etc.) & $\mathrm{O}$ & & & $\mathrm{O}$ & Information \\
\hline Transportation, Access & $\underline{0}$ & & & & Bus (Timetable and route) \\
\hline Restroom, Present location, Model courses & 0 & & & 0 & Map \\
\hline High light, Guidance, Transportation, Food (Shops) & 0 & & & 0 & Pop-up \\
\hline High light, Photos of seasons & & & & $c$ & Seasons Photo \\
\hline $\begin{array}{c}\text { Guidance, Origin, Photos of animals, flowers, } \\
\text { mountains }\end{array}$ & & & & $\mathrm{O}$ & Photo books \\
\hline Event & & & & 0 & Stamp rally \\
\hline SNS, "Like" & & & $\mathrm{O}$ & & SNS \\
\hline Multi lingual & 0 & & & & Setting \\
\hline
\end{tabular}

\section{DESIGN OF THE APPLICATION FOR OKU-} NIKKO INTRODUCTION

In this section, we explain how we designed our application based on discussion in section 6 .

\subsection{Home Screen of the Application}

In the home screen, we arranged functions based on levels of Maslow's hierarchy. We added higher priority to the lower level of need. We arranged higher priority function (= lower level) in the home screen, pop up, action bar and tab bar since they are easy to access.

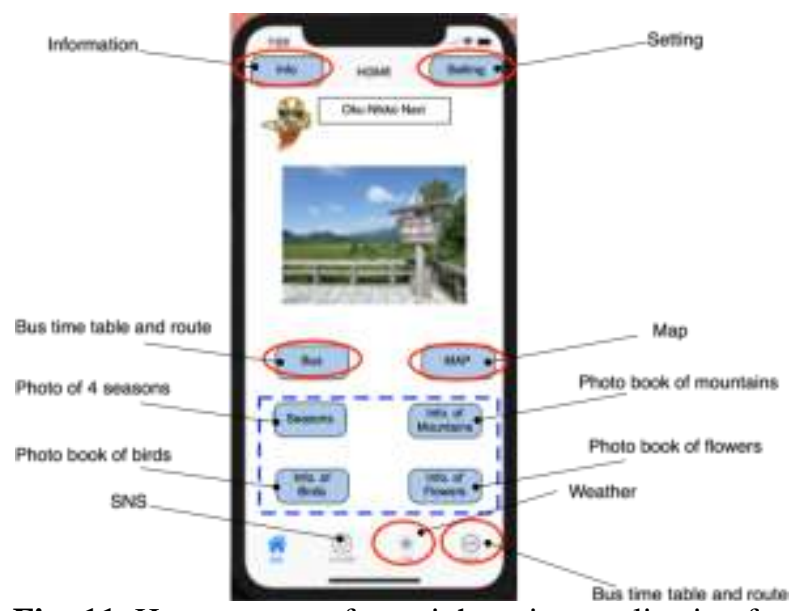

Fig -11: Home screen of our sightseeing application for Oku-Nikko.

Fig-11 shows the home screen. Red circles show functions relating to higher priority, level 1 and 2 of Maslow's hierarchy. Buttons in blue dotted line are relating to Zeigarnik Effect.

In section 7.2, the outline of each function is mentioned.

\subsection{Functions}

- Information

This function is used when real-time information is required. Such information is cannot be stored in the application when it was built so that this information is provided from a server immediately. For example, 
information of change of weather (such as thunderstorm), approaching of bear and the best timing of autumn leaves. Weather and risk of bear are relating to Safety needs (Level 2) and autumn leaves are relating to Aesthetic needs (Level 6).

- Bus Timetable

In Oku-Nikko, the transportation methods are Bus and car. There are comments at the interview that the location of a bus stop is difficult to find and timetable is also difficult to find [5]. We think that information relating to a bus is relating to Safety needs (Level 2) so that there is two access method in the home screen, one is in the center of the screen and another is in the tab bar. Also, we added a function to retrieve bus stop and timetable from the map. Fig-12 shows the screenshot of bus timetable.

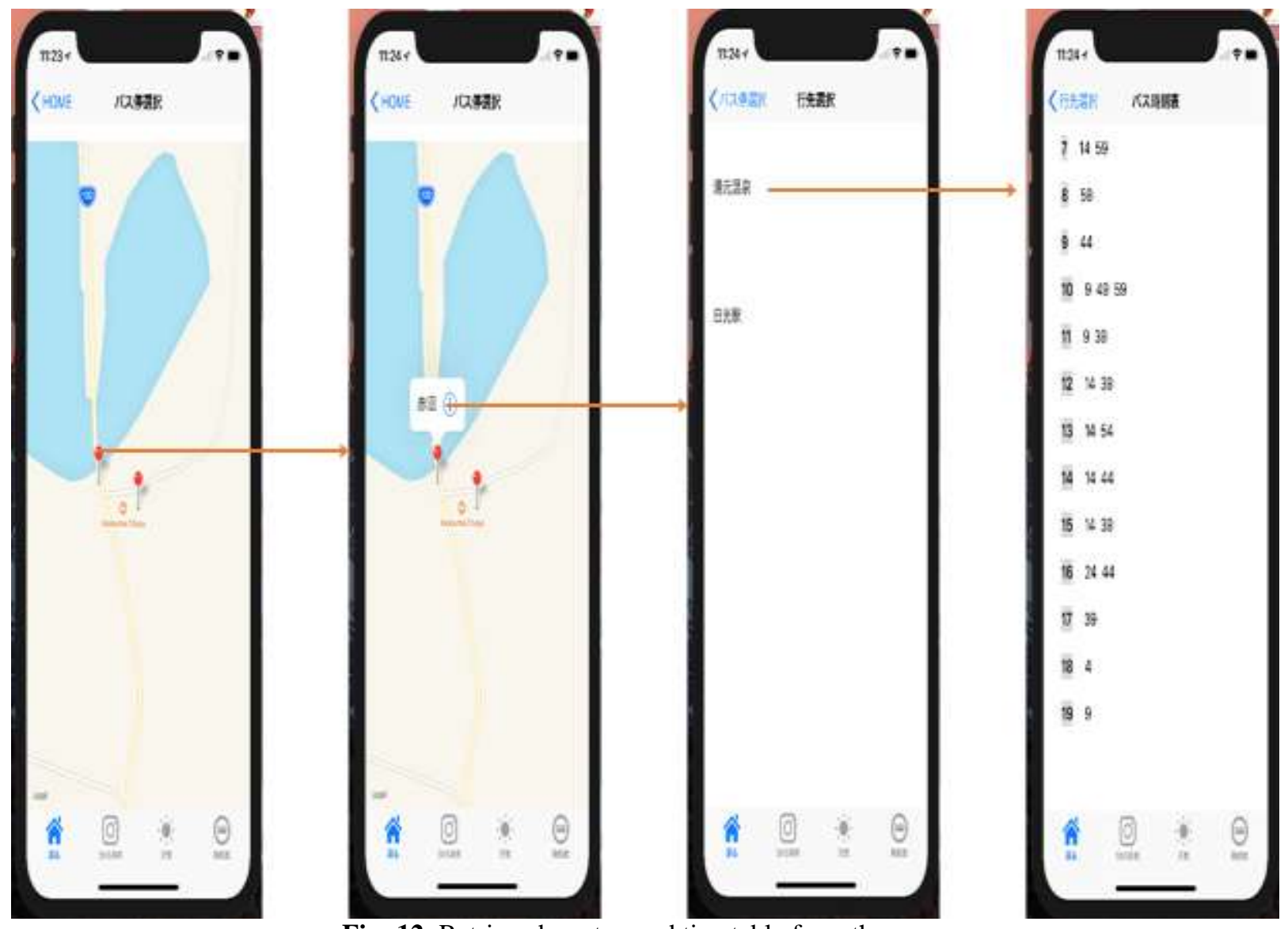

Fig -12: Retrieve bus stop and timetable from the map

\section{- Pop-up information}

Pop-up informationis a function to display information relating to BLE beacons that will be installed at the signboard and signpost. As same as "Nikko KamenNavi", this application displays pop up when it detects advertising message from a BLE beacon. The information displayed in the pop up is information of nature such as flower or bird around the area, history of the area, distance and estimated time to the nearest bus stop or high-lighted spots. This application also has a function of stamp rally by using BLE beacon. Distance and estimated time are relating to Safety needs (Level 2) and detailed information of a signboard is relating to Cognitive needs (Level 5).
- $\quad$ Photobook of seasons in Oku-Nikko

Oku-Nikko has differentfaces in different season, so that this function introduces beautiful photos of each season and may cause intention to return Oku-Nikko again. We think that this function causes Zeigarnik Effect to visitors to Oku-Nikko.

- Photobooks of nature in Oku-Nikko

Photobook of mountain, flower, and bird introduce mountains, flowers, and birds of Oku-Nikko by photo and text (Fig-13). This function satisfies the intellectual desire and relating to Cognitive needs (Level 5). Also, this function may cause repeating intention and relate to Zeigarnik Effect. 


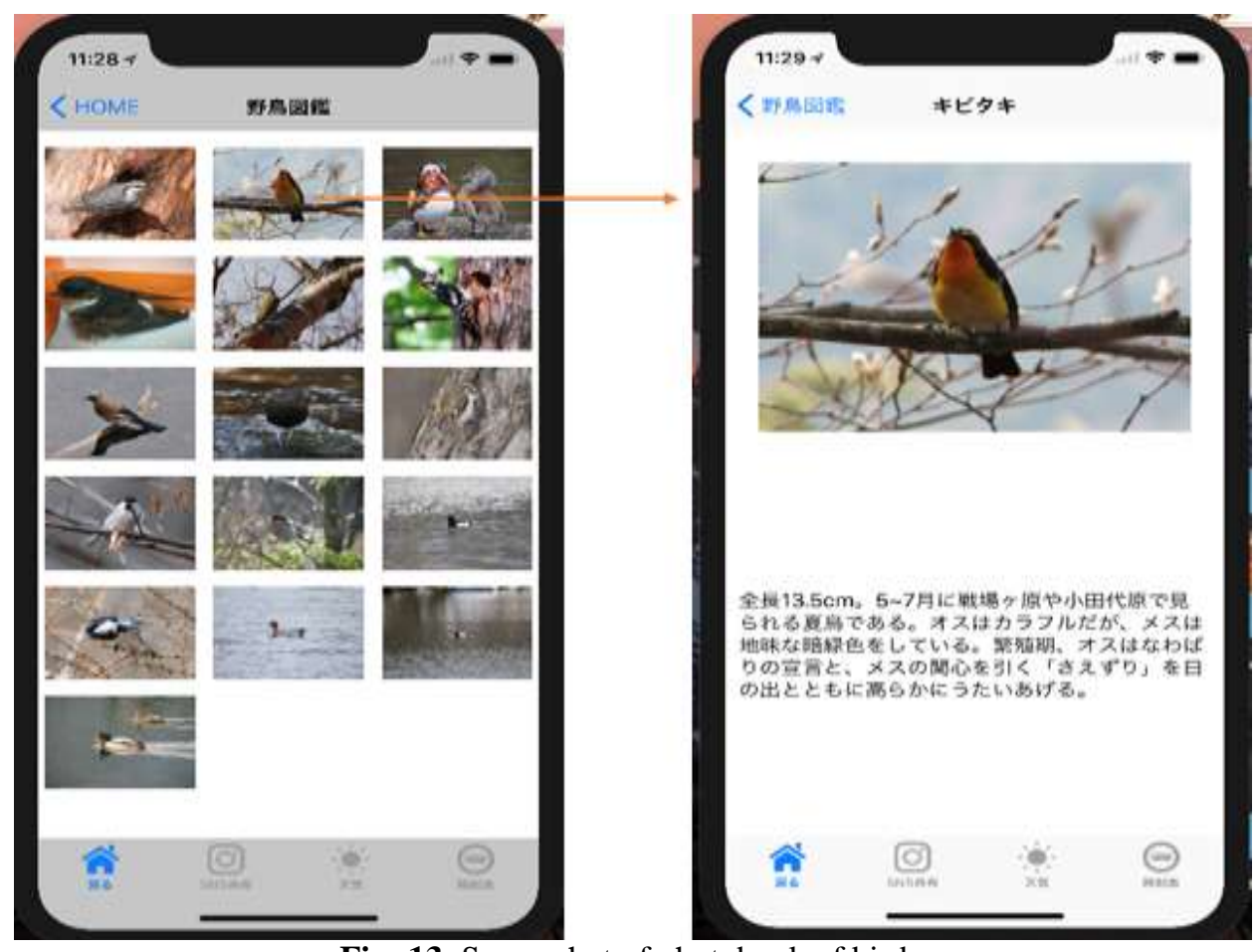

Fig -13: Screenshot of photobook of bird

\section{- Map}

The Map is used to display current position, the locationof a restroom, rest area, shops, visitor center. Also, it is possible to know detailed information of signboard (indicates by a pin in the map). Location of a restroom is relating to Biological and physiological needs (Level 1), current position and route are relating to Safety needs (Level 2) and detailed information of the area is relating to Cognitive needs (Level 5).

- $\quad$ SNS

This function is used to submit articles to Facebook,Instagram, and Twitter. Recently, many tourists send photo and impression of travel to the friends. This activity is relating to love and belongingness needs (Level 3) and esteem needs (Level 4). We think that this function is also important so that this function is stored in the tab bar to be accessible from any screen. The screenshot is in Fig-14.

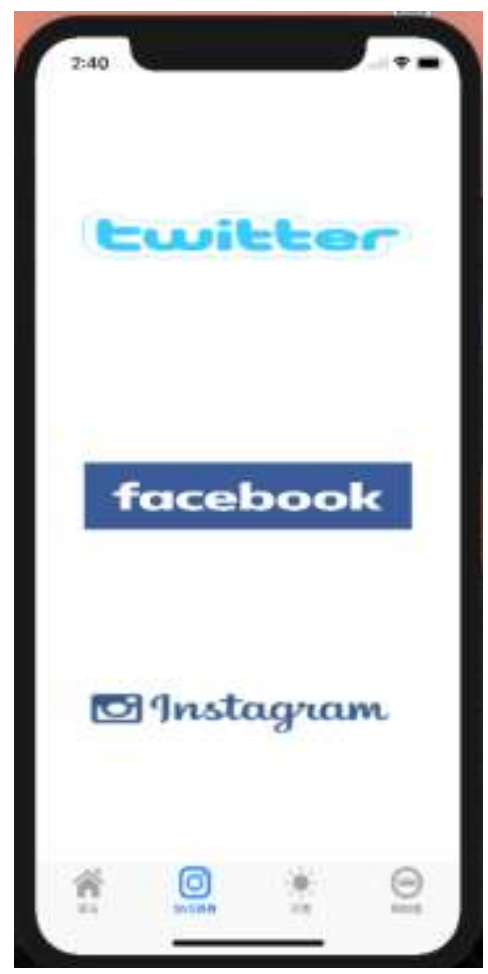

Fig -14: Screenshot of SNS access

- Weather

"Weather" is a part of Safety needs (Level 2) since weather is changing frequently in the mountain area. The requirements for security is important, so that there are two ways to access "Weather", one is in the information to access updated weather information and another is in the tab bar. 


\section{- $\quad$ Setting}

The "setting" provides a function to select the language. Language is the important issue for foreigners. In Nikko and Oku-Nikko area, there are many visitors from Thai and Taiwan, so that this application provides four languages such as Japanese, English, Thai, and Chinese (Traditional Chinese).

\section{CONCLUSION}

We explained smartphone application design method by using priority based on psychological effects, Zeikarnik Effect and Maslow's hierarchy of needs.

Firstly, we listed up required elements of sightseeing and categorized into 10 categories. Then we added priority to them based on Maslow's hierarchy of needs. At last, we added priority to functions of a mobile phone application based on the mapping of elements of sightseeing and Maslow's hierarchy of needs.Baes on this analysis, we designed our sightseeing application for Oku-Nikko.For example, all higher priority function (Level 1 and 2 of Maslow's hierarchy) are accessible from home screen and some of them are in the tab bar to be accessible from all screen.

We addedphoto book of seasons on the home screen to use Zeigarnik Effect to encourage visitors to visit Oku-Nikko again in the different seasons. Also, we expect that photo books of nature (mountain, flower, bird) may cause a similar effect.

The Ministry of the Environment has been promoting "the Project to Fully Enjoy National Parks [33]" at eight national parks in Japan since 2016 and Nikko National Park is one of the selected areas. One of the missions of the project is to support the national park by ICT. This application will be designed to support this mission and will start to use from May 2018. After service-in, we would like to evaluate the effect of our design method and apply the design method to mobile applications for different purposes. For example, recently, agri-tourism is getting popular in Thailand among senior European people [23,24] and in Japan for young people $[25,26]$. In such case, our idea to design application for agri-tourism may be useful to design different target age and different requirements for safety and biological needs.

\section{ACKNOWLEDGEMENT}

Authors would like to express special thanks to Mr.Wada and Mr.Suzuki of Nikko National Park Office of Ministry of the Environment, Ms.Wada and Ms.Sato of Tochigi Prefectural Government Office and all members of the committee for increasing satisfaction of tourists in Nikko. They provided us information of Oku-Nikko and valuable advice.

This research is supported by JSPS KAKENHI Grant Number JP17H02249. Also, the basis of this research was performed as a project of SCOPE (142303001).

\section{REFERENCES}

[1] Bluetooth SIG, "Specification of the Bluetooth System", 2001. [Online]. Available:http://blog.bluetooth.com/bluetooth-sigintroduces-new-bluetooth-4-1-specification/.

[Accessed: 7- Aug- 2017].

[2] Bluetooth SIG, "Bluetooth SIG Introduces New Bluetooth 41 Specification", 2013. [Online]. Available: http://blog.bluetooth.com/bluetooth-sigintroduces-new-bluetooth-4-1-specification/. [Accessed: 7- Aug- 2017].

[3] Atsushi Ito 、Yuko Hiramatsu 、 HiryukiHatano 、 Mie Sato, Fumihiro Sato 、 Akira Sasaki 、Yu Watanabe、"Recovering the Traditional Street with BLE Beacons Based on Classification of Travelers," International Journal of Embedded Systems (IJES) (2016.2.28)

[4] Yuko Hiramatsu, Fumihiro Sato, Atsushi Ito, Hiroyuki Hatano, Mie Sato, Yu Watanabe, Akira Sasaki, "A Study of Designing Service Model for Sightseeing Using BLE Beacons -To Provide Tourism Information of Traditional Cultural Sites-", International Journal on Advances in Intelligent Systems, vol.9 no 3 \& 4, year 2016, pp442-451 (2016.12)

[5] Yuko Hiramatsu, Fumihiro Sato, Atsushi Ito, Hiroyuki Hatano, Mie Sato, Yu Watanabe, Akira Sasaki,"Designing Mobile Application to Motivate Young People to Visit Cultural Heritage Sites", International Journal of Social, Behavioral, Educational, Economic, Business and Industrial Engineering Vol:11, No:1, 2017, pp.121-128 (2017.1)

[6] Ministry of Internal Affairs and Communications, "SCOPE", $2017 . \quad$ [Online]. Available:http://www.soumu.go.jp/main_sosiki/joho_ tsusin/scope/. (in Japanese) [Accessed: 7- Aug- 2017].

[7] Ministry of Internal Affairs and Communications, "MIC", 2017.2 [Online]. Available:http://www.soumu.go.jp/english/index.htm 1. [Accessed: 7- Aug- 2017].

[8] Japan Society of Promotion of Science, "KAKENHI", 2017. [Online].

Available:https://www.jsps.go.jp/english/egrants/index.html. [Accessed: 7- Aug- 2017].

[9] "Tourism promotion plan for Nikko",

[10] http://www.city.nikko.lg.jp/kouryuu/gyousei/shisei/k ankoukenseibi/documents/kankoshinkokeikaku.pdf, 2014.3, (in Japanese)

[11] YoheiKurata, Misaki Aoki, Hisatoshi AI, "Outline of local Apps in Japan (in Japanese)", $12^{\text {th }}$ Symposium of Society for Tourism Informatics, pp.68-69, 2015

[12] Tag Cloud, "Technologies lead to Adaptability and lifelong engagement with culture throughout the CLOUD project", 2015. [Online]. Available:

[13] http://www.tagcloudproject.eu. [Accessed: 7- Aug2017]. 
[14] B. V. Zeigarnik, "On finished and unfinished tasks." In W. D. Ellis (Ed.), A sourcebook of Gestalt psychology, New York: Humanities Press, 1967

[15] Schiffman, Noah; Greist-Bousquet, Suzanne, "The effect of task interruption and closure on perceived duration", Bulletin of the Psychonomic Society, Vol 30(1), Jan 1992, 9-11.

[16] P. L. Pearce and P. F. Stringer, "The effect of task interruption and closure on perceived duration," Annals of Tourism Research 18, pp.136-154, 1991.

[17] Fridgen, J.D.: Environmental psychology and tourism. Annals of Tourism Research 11(1), 19-39 (1984)

[18] Van Raaij, W.E.: Consumer Research on tourism: Mental and behavioral constructs. Annals of Tourism Research 13, 1-9 (1986)

[19] T.Sasaki, "Psychology of Tourism," Kitahojishobou, Kyoto, pp. 51-59, 2007.

[20] Nikko City, "Information of Nikko", 2017. [Online]. Available:http://www.city.nikko.lg.jp.e.tj.hp.transer.c om. [Accessed: 7- Aug- 2017].

[21] Toshogu, "Introduction of Toshogu", 2017. [Online]. Available: http://www.toshogu.jp/english/index.html. [Accessed: 7- Aug- 2017].

[22] Trip advisor, "The most popular spot for visitors to Japan 2015”, 2015. [Online]. Available:http://tg.tripadvisor.jp/news/ranking/inboun dattraction_2015/. [Accessed: 7- Aug- 2017].

[23] Ueda K., "A psychophysiological approach towards understanding emotions", In Fukuda S. (Ed.), Emotional Engineering Vol.3. Switzerland, Springer International Publishing, pp.105-116, (2015)

[24] Atsushi Ito, Satoshi Nakagawa: "Expectology", Position paper for the workshop "Theories Behind UX Research and How They are Used in Practice" of CHI (The ACM SIGCHI Conference on Human Factors in Computing Systems) 2012. http://di.ncl.ac.uk/uxtheory/workshop-papers/, 4 Pages, Austin, USA (2012.5)

[25] RaneeEsichaikul,"Learning through Interpretation of European Senior Tourists in Thailand: Slow Tourism Domain", Proceedings of Fourth International Journal of Arts and Sciences Conference for Academic Disciplines, Harvard University, USA, 2630 May 2013.

[26] RaneeEsichaikul, "Travel Motivations, Behavior, and Requirements of European Senior Tourists to Thailand", PASOS Journal of Tourism and Cultural Heritage, Vol. 10, No. 12, 47-58, 2012.

[27] HAYASHI Takuya, "Sustainable Systems of Agritourism in a Cherry-growing Area: A Case Study of the Miizumi Area, Sagae City, Yamagata Prefecture", Geographical review of Japan series B, Special Issue: The Commodification of Rural Spaces in Japan,Vol. 82-2, pp. 60-77, (2009)

[28] http://www.jnto.go.jp/eng/location/routes/g_route/gol den_48.html[2018/2/18]

[29] Ricardo Anacleto, Lino Figueiredo, Ana Almeida, Paulo Novais, "Mobile application to provide personalized sightseeing tours", Journal of Network and Computer Applications, Volume 41, Pages 56-64, May 2014

[30] Alexander V. Smirnov, Alexey M. Kashevnik, Andrew Ponomarev, "Context-based infomobility system for cultural heritage recommendation: Tourist Assistant-TAIS", Personal and Ubiquitous Computing, Volume 21, Issue 2, pp 297-311, April 2017

[31] Natasha BulatovicTrygg and Mika Luimula, "Cultural Heritage in a Pocket - Case Study "Turku Castle in Your Hand", CoginfoCom 2016, Oct.2016

[32] Miroslav Macik, Ivo Maly, Eva Lorencova, Tomas Flek and ZdenekMikovec, "Smartphoneless contextaware indoor navigation", CoginfoCom 2016, Oct.2016

[33] Maslow, A. H. (1987). Motivation and personality (3rd ed.). Delhi, India: Pearson Education.

[34] McLeod, S. A. (2017). Maslow's hierarchy of needs. Retrieved from www.simplypsychology.org/maslow.html[2018/2/16]

[35] http://www.env.go.jp/en/nature/enjoyproject/index.html[2018/2/18]

[36] https://www.nikko-nsm.co.jp [2018/2/17]

[37] http://www.mlit.go.jp/kankocho/shisaku/kokusai/ict.h tml [2017/12/26]. 